\title{
DOES LUMBOSACRAL TRANSITIONAL VERTEBRAE CAUSE LOW BACK PAIN?
}

\author{
๑ Gökhan Kürșat KARA ${ }^{1}$, ๑ Hüseyin KAVAK² \\ ${ }^{1}$ istinye University Faculty of Medicine, Department of Orthopaedic and Traumatology, İstanbul, Turkey \\ 2Liv Hospital, Clinic of Orthopaedic and Traumatology, Istanbul, Turkey
}

\begin{abstract}
Objective: Lumbosacral transitional vertebra (LSTV) is the most common congenital anomaly of the lumbosacral area. Its prevalence varies between $4 \%$ and $35.9 \%$, and its relationship with back pain is controversial. In this study, we aimed to investigate the relationship of LSTV with low back pain by comparing the prevalence of LSTV between nonspecific low back pain and abdominal pain.

Materials and Methods: A total of 411 radiographs from patients with nonspecific low back pain (group 1) and 520 radiographs from patients with abdominal pain (group 2) were included in the study. Data were evaluated according to Castellvi's radiographic classification, and the prevalence of LSTV was reported.

Results: According to Castellvi's classification, the prevalence of LSTV was $27.5 \%$ and $36.7 \%$ in groups 1 and 2, respectively. LSVT types la, Ib and IIIb were the most common types.

Conclusion: In abdominal pain group (group 2), which was used as the control group in our study, statistically significantly $(p<0.05)$ more LSTV was found compared to the nonspecific low back pain group (group 1). Therefore, no correlation was found between LSTV and nonspecific low back pain.

Keywords: Lumbosacral transitional vertebra, sacralisation, lumbalisation, low back pain
\end{abstract}

\section{INTRODUCTION}

Lumbosacral transitional vertebra (LSTV), which is a congenital vertebral anomaly, is a condition in which the last vertebra in the lumbosacral transitional area exhibits both sacral and lumbar morphology. LSTV is the most common malformation of this region, and its incidence in the general population varies between $4 \%$ and $35.9 \%^{(1-3)}$.

LSTV anomalies, which include sacralisation or lumbalisation, are often detected accidentally ${ }^{(4,5)}$. The fusion of the fifth lumbar vertebra with the first sacral segment in varying degrees is called sacralisation, and the sacral segment having transverse processes similar to the morphology of the lumbar vertebra is called lumbalisation. Awareness of these conditions guides physicians in the differential diagnosis of idiopathic low back pain and in determining the vertebral level indicated for surgery ${ }^{(1)}$. The relationship between LSTV and low back pain has been the subject of many studies ${ }^{(1,4,6)}$. Although some studies have advocated that LSTV causes low back pain, some have not found a positive correlation between LSTV and mechanical low back pain ${ }^{(7,8)}$.
In this study, we aimed to investigate the frequency of LSTV between a group of patients who presented to our clinic with nonspecific low back pain and a control group with abdominal pain.

The classification of LSTV was made in 1984 by Castellvi et al.(7) based on some features in radiological images. Accordingly, the condition has four types (Table 1, Figures 1-7).

Table 1. Castellvi's radiographic classification of lumbosacral transitional vertebra

\begin{tabular}{|ll|}
\hline Type la & $\begin{array}{l}\text { Unilateral, TP height equal to or greater than } 19 \\
\mathrm{~mm}\end{array}$ \\
\hline Type Ib & Bilateral, TP height equal to or greater than $19 \mathrm{~mm}$ \\
\hline Type Ila & Presence of unilateral articulation of TP and sacrum \\
\hline Type IIb & Presence of bilateral articulation of TP and sacrum \\
\hline Type IIla & Unilateral fusion of TP with sacrum \\
\hline Type IIlb & Bilateral fusion of TP with sacrum \\
\hline Type IV & $\begin{array}{l}\text { Fusion of Type Ila on one side and Type III on the } \\
\text { contralateral side }\end{array}$ \\
\hline
\end{tabular}

TP: The lowest lumbar transverse process

Address for Correspondence: Gökhan Kürşat Kara, stinye University, Department of Orthopaedic and Traumatology, İstanbul, Turkey E-mail: drkursatkara@yahoo.com Received: 07.10.2020 Accepted: 26.10.2020

ORCID ID: orcid.org/0000-0002-2058-6534 
In light of the current literature, no standard imaging method is used to detect LSTV( ${ }^{(8)}$. In addition, an important referential finding in the differentiation of sacralisation from lumbalisation has been reported as the location of the iliolumbar ligament at the $\mathrm{L} 5$ level in axial computed tomography sections and magnetic resonance imaging $(\mathrm{MRI})^{(9)}$. Although LSTV anomalies are common in the general population, their role in low back pain is still controversial ${ }^{(10)}$.

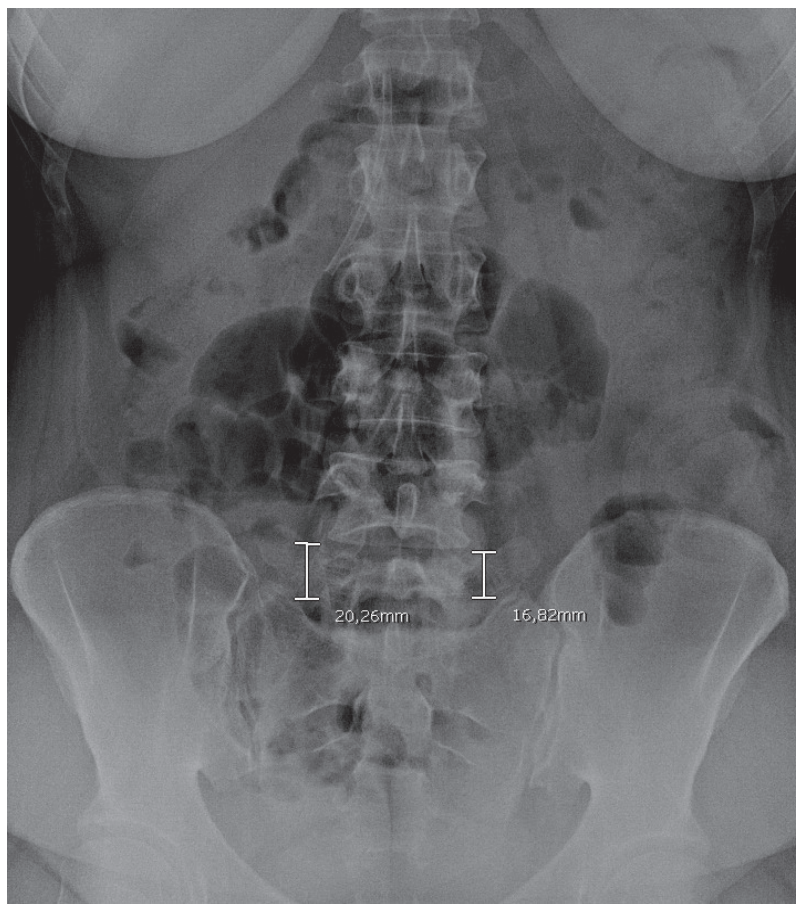

Figure 1. Castellvi radiographic classification Type la

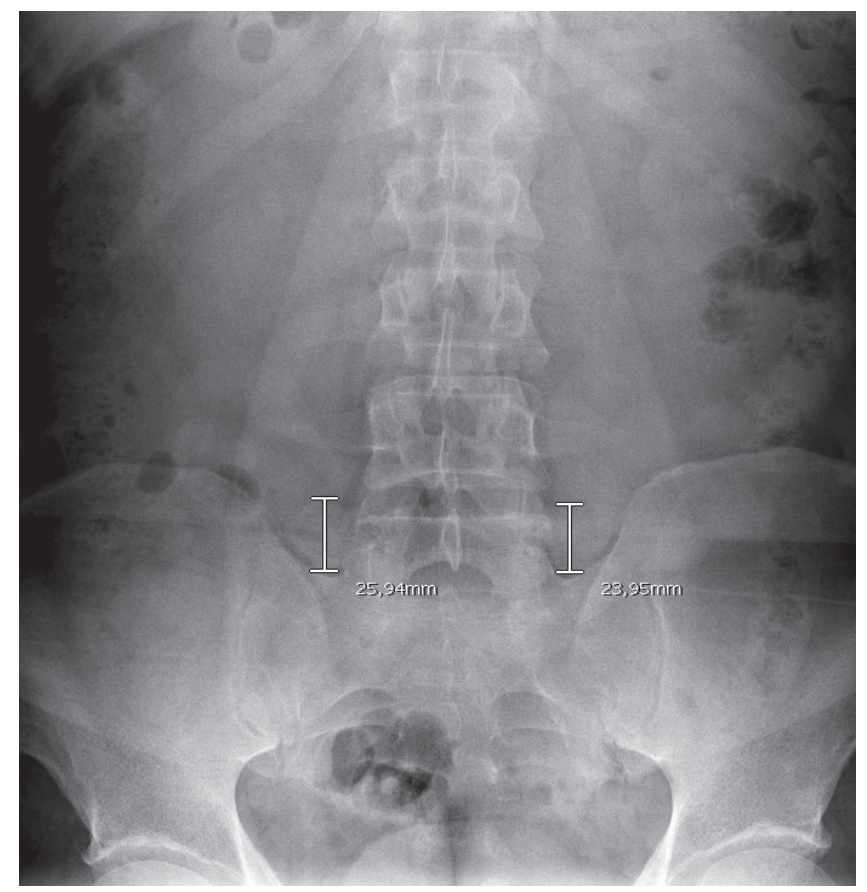

Figure 2. Castellvi radiographic classification Type lb
In this study, we tried to reveal the frequency of LSTV and its relationship with nonspecific low back pain by retrospectively evaluating the radiographs of patients with nonspecific low back pain and abdominal pain.

\section{MATERIALS AND METHODS}

After the approval of the Ethics Committee of İstinye University (approval number: 2/2020.K-035), two-way lumbar radiographs

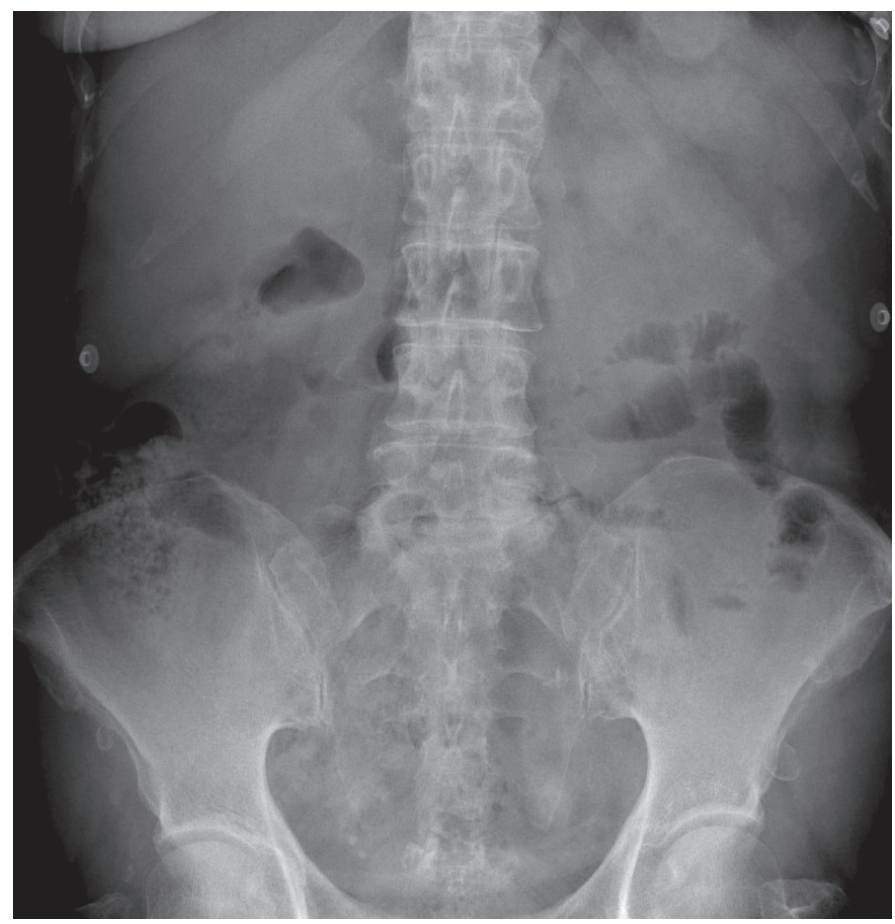

Figure 3. Castellvi radiographic classification Type Ila

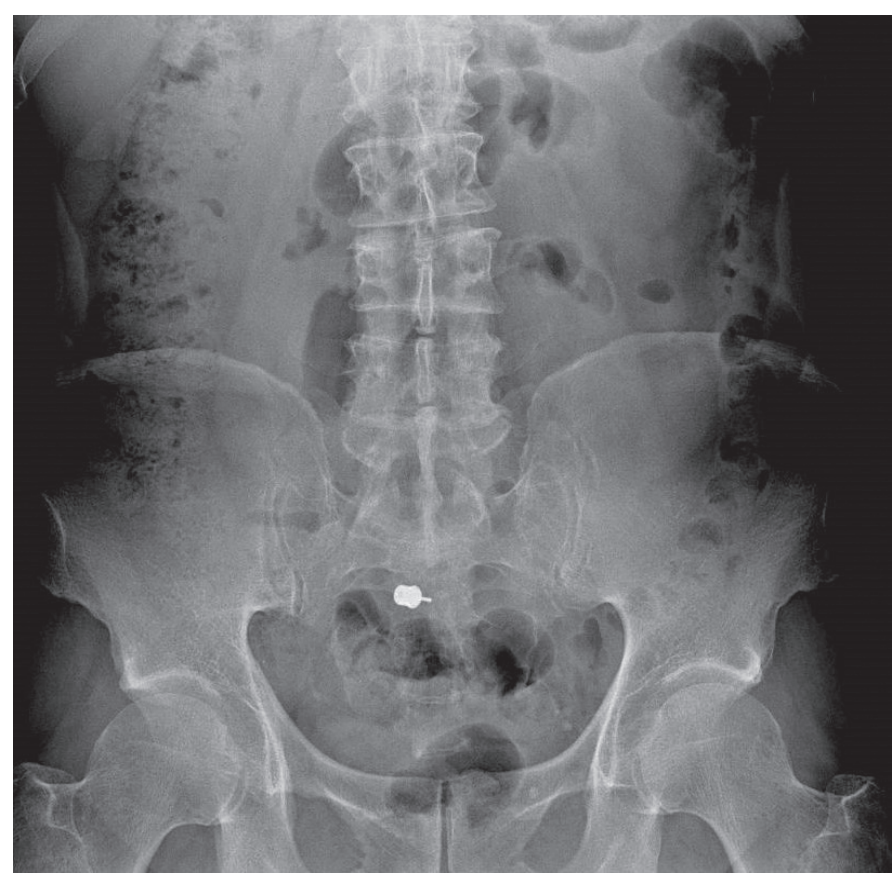

Figure 4. Castellvi radiographic classification Type Ilb 
turkishspine

of patients admitted to our hospital with nonspecific low back pain (group 1) and standing direct abdominal radiographs of patients who presented with abdominal pain (group 2) were examined retrospectively.

Images were obtained from the SYNAPSE (PACS) system (Fujifilm Global, Tokyo, Japan) available at our hospital. Radiographs that clearly showed the articulation of the $12^{\text {th }}$ rib

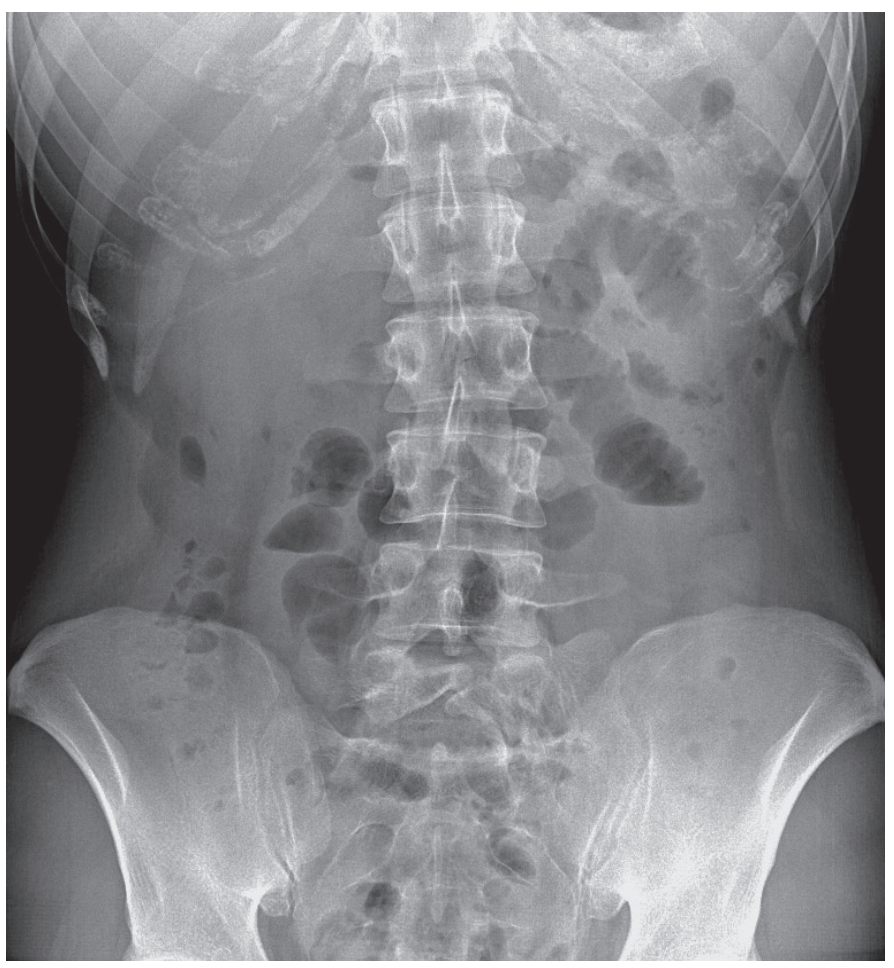

Figure 5. Castellvi radiographic classification Type IIIa

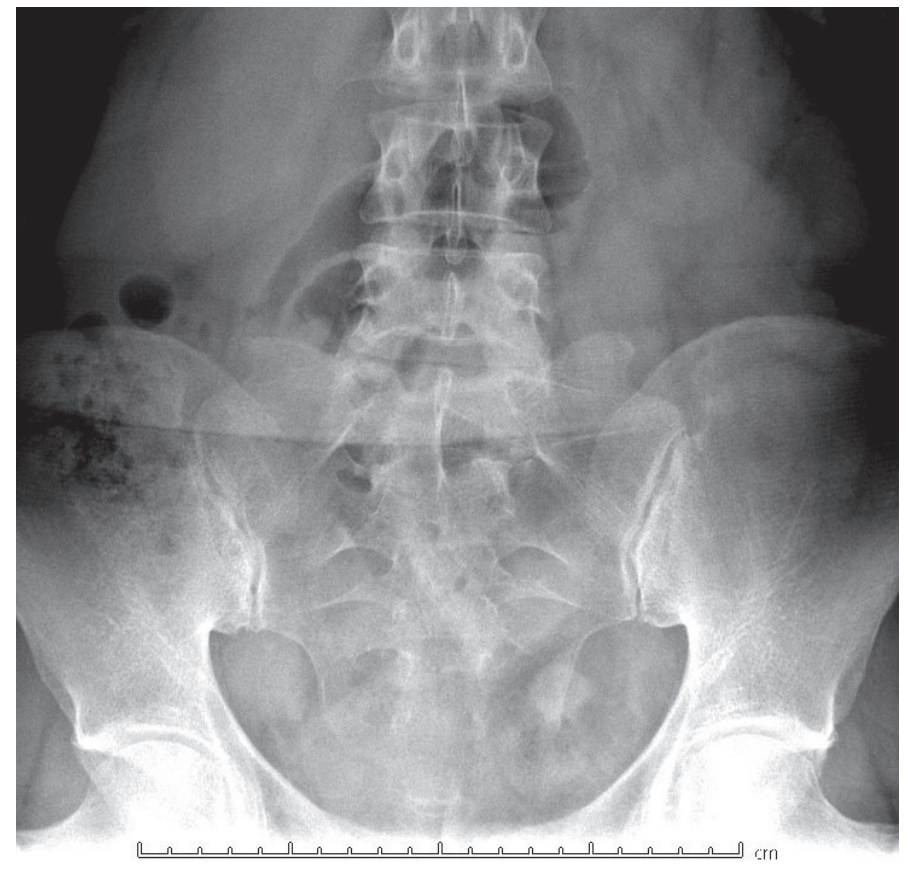

Figure 6. Castellvi radiographic classification Type IIIb with the T12 vertebra, sacral wings and transverse processes of the lumbar vertebrae were evaluated. Patients with a history of trauma, history of lumbar surgery, neurological findings of the lower extremity, a positive Lasègue test, a known malignancy, spondylolisthesis, spinal fractures and spine infections, patients who lacked optimal images due to advanced osteoporosis and abdominal gases, scoliosis patients with lumbar Cobb's angle $>10^{\circ}$ and patients aged $<18$ years were excluded from the evaluation. A total of 411 patients in group 1 and 520 patients in group 2 were included in the study. Data were evaluated according to Castellvi's radiographic classification, and the prevalence of LSTV was reported.

\section{RESULTS}

From a total of 931 patients, 411 with nonspecific low back pain (group 1; 175 men, 236 women) and 520 with abdominal pain (group 2; 246 men, 274 women) were evaluated. The prevalence of LSVT was $27.5 \%$ in group 1 and $36.7 \%$ in group 2. According to Castellvi's classification of LSTV, 38 patients (9.2\%) had Type la, 35 (8.5\%) had Type Ib, 10 (2.4\%) had Type Ila, 11 (2.7\%) had Type IIb, four (1.0\%) had Type IIla, 13 (3.2\%) had Type IIIb and one (0.2\%) had Type IV LSTV in group 1 . In group 2, 74 patients (14.2\%) had Type Ia, 54 (10.4\%) had Type Ib, 13 (2.5\%) had Type Ila, nine (1.7\%) had Type IIb, four $(0.8 \%)$ had Type IIIa, 30 (5.8\%) had Type IIIb and seven (1.3\%) had Type IV LSTV. The most frequently observed LSTV types were Type la, $\mathrm{Ib}$ and IIIb. The average patient age was 45.2 (range: 18-83) years in group 1 and 41.5 (range: $18-81$ ) years in group 2, and the difference between the two groups was not statistically significant $(p=0.06)$.

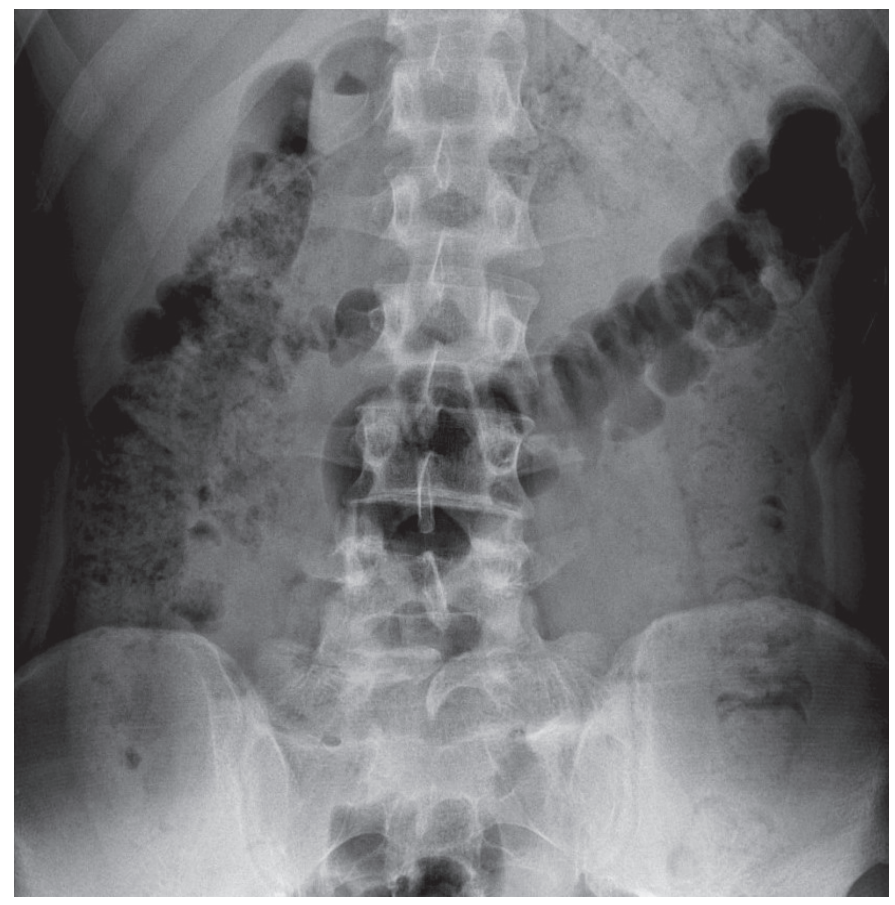

Figure 7. Castellvi radiographic classification Type IV 


\section{Statistical Analysis}

Data analysis was performed using SPSS (IBM, Armonk, NY, USA). Datas on age were expressed in mean and standard deviation. Chi-square test was utilized to compare LSTV, subtypes of LSTV, gender between two groups. The Mann-Whitney $U$ test was used to compare continuous variables. (such as age ofpatients). A $p$ value of $<0.05$ was considered statistically significant.

\section{DISCUSSION}

To the best of our knowledge, no large-scale studies have determined the prevalence of LSTV in Turkey. In previous studies, the incidence of LSTV ranged from $4 \%$ to $35.9 \%^{(1-3)}$. This wide range in prevalence was associated with intercommunal differences, differences in classification and radiological evaluation errors ${ }^{(11)}$. Tini et al. ${ }^{(12)}$ examined 4,000 radiographs and reported LSTV prevalence of $6.7 \%$, Nardo et al. ${ }^{(13)}$ reported a prevalence of $18.1 \%$ in 4,636 radiographs and Luoma et al. ${ }^{(14)}$ reported a prevalence of $30 \%$ in a population of 163 men. In another study, Uçar et al.(15) determined the prevalence of LSTV as $18.9 \%$ over 3,607 radiographs. Among routine radiographs, LSTV can be best detected by lumbosacral radiographs and standing direct abdominal radiographs. Therefore, we included patients who presented to our hospital for nonspecific low back pain and abdominal pain.

The exact origin of LSTV is unknown ${ }^{(16)}$. Some studies have asserted that Castellvi Type I transitional vertebra has no clinical and surgical significance ${ }^{(17,18)}$. However, since otherwise would cause confusion in calculating the prevalence of LSTV, Castellvi Type I was also evaluated in our study. From a statistical perspective, even when Castellvi Type I cases were excluded from both groups, LSTV prevalence did not differ significantly between group 1 (35.5\%) and group 2 (32.9\%) ( $p=0.7)$. However, if these rates were examined by sex, the prevalence of Castellvi Type II and higher was significantly greater in women than in men $(p<0.000)$.

The L5-S1 level is a frequent site of surgical procedures ${ }^{(19)}$. Studies have reported a correlation problem between the clinical evaluation of patients with LSTV and imaging ${ }^{(7,20)}$. Spinal surgeries performed at the wrong vertebral level pose a serious medicolegal problem. For this reason, identifying the vertebral level in spinal surgery, especially in individuals with LSTV, is significant ${ }^{(16)}$. Radiographs must be evaluated before surgery. Vertebral level-related errors are more often encountered when surgical planning is done using MRI alone without radiography ${ }^{(21)}$. This puts a financial burden on both the patient and hospital and increases the risk of postoperative complications and re-surgery. For this reason, physicians dealing with spinal surgery should make additional efforts to determine the level of LSTV and compare the lumbosacral radiographs with MRI and fluoroscopy images taken during surgery $(3,7,20)$.

\section{Study Limitations}

There were limitations to our current study of note. Because this was small sample size and a retrospective study. MRI would have detected more spinal abnormalities such as annular tears, disc herniations, end-plate changes, and spinal or foraminal stenosis, which would have provided a better estimate of the distribution of other spinal problem.

\section{CONCLUSION}

In conclusion, no correlation was found between the presence of LSTV and nonspecific low back pain. LSTV is a common anomaly in our population and should be kept in mind during surgical planning and intraoperative level determination.

\section{Ethics}

Ethics Committee Approval: This study approved by İstinye University Ethics Committee (approval number: 2/2020.K-035).

Informed Consent: Retrospective study.

Peer-review: Internally peer-reviewed.

\section{Authorship Contributions}

Concept: G.K.K., H.K., Design: G.K.K., H.K., Data Collection or Processing: G.K.K., Analysis or Interpretation: G.K.K., Literature Search: G.K.K., H.K., Writing: G.K.K., H.K.

Conflict of Interest: No conflict of interest was declared by the authors.

Financial Disclosure: The authors declared that this study received no financial support.

\section{REFERENCES}

1. Konin GP, Walz DM. Lumbosacral transitional vertebrae: classification, imaging findings, and clinical relevance. AJNR Am J Neuroradiol. 2010;31:1778-86.

2. Paik NC, Lim CS, Jang HS. Numeric and morphological verification of lumbosacral segments in 8280 consecutive patients. Spine (Phila Pa 1976). 2013;38:E573-8.

3. Tang M, Yang XF, Yang SW, Han P, Ma YM, Yu H, et al. Lumbosacral transitional vertebra in a population-based study of 5860 individuals: prevalence and relationship to low back pain. Eur J Radiol. 2014;83:1679-82.

4. Jenkins EM, Borenstein DG. Exercise for the low back pain patient. Baillieres Clin Rheumatol. 1994;8:191-7.

5. Dreyer SI, Dreyfuss PH. Low back pain and the zygapophysial (facet) joints. Arch Phys Med Rehabil. 1996;77:290-300.

6. Kılınçoğlu V. Prevalance evaluation of lumbosacral transitiona vertebrae in Kahramanmaras population by large-scale screening. [Article in Turkish] Eur Arc Med Res. 2017;33:134-8.

7. Castellvi AE, Goldstein LA, Chan DP. Lumbosacral transitional vertebrae and their relationship with lumbar extradural defects. Spine (Phila Pa 1976). 1984;9:493-5.

8. Hughes RJ, Saifuddin A. Numbering of lumbosacral transitional vertebrae on MRI: role of the iliolumbar ligaments. AJR Am J Roentgenol. 2006;187:W59-65.

9. Carrino JA, Campbell PD Jr, Lin DC, Schweitzer ME, Flanders AE, Eng l, et al. Effect of spinal segment variants on numbering vertebral levels at lumbar MR imaging. Radiology. 2011;259:196-202.

10. Oğuz H, Akkuş S, Tarhan S, Açikgözoğlu S, Kerman M. Measurement of spinal canal diameters in young subjects with lumbosacral transitional vertebra. Eur Spine J. 2002;11:115-8. 
turkishspine

11. Bron JL, van Royen BJ, Wuisman PI. The clinical significance of lumbosacral transitional anomalies. Acta Orthop Belg. 2007;73:687-95.

12. Tini PG, Wieser C, Zinn WM. The transitional vertebra of the lumbosacral spine: its radiological classification, incidence, prevalence, and clinical significance. Rheumatol Rehabil. 1977;16:180-5.

13. Nardo L, Alizai H, Virayavanich W, Liu F, Hernandez A, Lynch JA, et al. Lumbosacral transitional vertebrae: association with low back pain. Radiology. 2012;265:497-503.

14. Luoma K, Vehmas T, Raininko R, Luukkonen R, Riihimäki $H$. Lumbosacral transitional vertebra: relation to disc degeneration and low back pain. Spine (Phila Pa 1976). 2004;29:200-5.

15. Uçar D, Uçar BY, Coşar Y, Emrem K, Gümüşsuyu G, Mutlu $S$, et al. Retrospective cohort study of the prevalence of lumbosacral transitional vertebra in a wide and well-represented population. Arthritis. 2013;2013:461425.

16. Nakagawa T, Hashimoto $K$, Tsubakino $T$, Hoshikawa $T$, Inawashiro T, Tanaka Y. Lumbosacral Transitional Vertebrae Cause Spinal Level Misconception in Surgeries for Degenerative Lumbar Spine Disorders. Tohoku J Exp Med. 2017;242:223-8.
17. Wigh RE, Anthony HFJr. Transitional lumbosacral discs. probability of herniation. Spine (Phila Pa 1976). 1981;6:168-71.

18. de Bruin F, Ter Horst S, Bloem JL, van den Berg R, de Hooge M, van Gaalen $F$, et al. Prevalence and clinical significance of lumbosacral transitional vertebra (LSTV) in a young back pain population with suspected axial spondyloarthritis: results of the SPondyloArthritis Caught Early (SPACE) cohort. Skeletal Radiol. 2017;46:633-9.

19. Rengachary SS, Ellenbogen RG. Principles of Neurosurgery. 2nd ed. Philadelphia, PA: Elsevier; 2005.

20. Vergauwen S, Parizel PM, van Breusegem L, Van Goethem JW, Nackaerts Y, Van den Hauwe L, et al. Distribution and incidence of degenerative spine changes in patients with a lumbo-sacral transitional vertebra. Eur Spine J. 1997;6:168-72.

21. O'Driscoll CM, Irwin A, Saifuddin A. Variations in morphology of the lumbosacral junction on sagittal MRI: correlation with plain radiography. Skeletal Radiol. 1996;25:225-30. 